\title{
Case Report \\ Staphylococcal Toxic Shock Syndrome Caused by Tampon Use
}

\author{
Cian McDermott and Michael Sheridan \\ Emergency Department, University Hospital Geelong, Ryrie Street, Geelong, VIC 3220, Australia \\ Correspondence should be addressed to Cian McDermott; cianmcdermott@gmail.com
}

Received 21 October 2014; Accepted 8 January 2015

Academic Editor: Martin Albert

Copyright (c) 2015 C. McDermott and M. Sheridan. This is an open access article distributed under the Creative Commons Attribution License, which permits unrestricted use, distribution, and reproduction in any medium, provided the original work is properly cited.

The authors report a case of near-fatal sepsis with multiorgan failure resulting from a Staphylococcal tampon-associated toxic shock syndrome, requiring a lengthy critical care admission. Successful treatment of this condition focuses on early identification, source control, and administration of antimicrobial agents. Intravenous immunoglobulin therapy used early may prevent widespread tissue necrosis.

\section{Case Report}

A 15-year-old Caucasian schoolgirl presented to the Emergency Department (ED) complaining of a single day history of lower abdominal pain, muscle aches, diarrhoea, and vomiting. She had a tampon in situ for 24 hours for menstrual bleeding. She had been undergoing treatment for thyroid nodular disease using carbimazole $10 \mathrm{mg}$ twice daily, which she had ceased 3 days previously.

On initial examination, the patient was hypotensive (systolic blood pressure $75 \mathrm{mmHg}$ ), pyrexic (temperature $39.4^{\circ} \mathrm{C}$ ), and tachycardic (heart rate $150 /$ minute). There were signs of multiorgan dysfunction as her skin peripheries were profoundly vasoconstricted and mottled with a significant delay in capillary refill time (10 seconds) and an elevated serum lactate $(13.0 \mathrm{mmol} / \mathrm{L})$. The patient was acutely confused and intermittently drowsy. There was a generalized lower abdominal tenderness. Vaginal examination revealed a malodorous tampon, coated in a green mucopurulent discharge, which was removed.

The patient was sedated, intubated, and ventilated in the ED. Vasopressor support, aggressive fluid resuscitation in addition to broad-spectrum, empirical antibiotics (vancomycin, flucloxacillin, piptazobactam, and clindamycin) for sepsis of unknown origin and intravenous immunoglobulin treatment, was commenced. Initial investigations showed a white cell count of $17.4 \times 10^{9} / \mathrm{L}$, neutrophil count of $16.4 \times$ $10^{9} / \mathrm{L}$, CRP of $206 \mathrm{mg} / \mathrm{L}$, and a venous serum $\mathrm{pH}$ of 7.03 , with a base excess of $-18.5 \mathrm{mmol} / \mathrm{L}$ and a bicarbonate level of $12 \mathrm{mmol} / \mathrm{L}$. High vaginal swabs returned a heavy growth of methicillin-susceptible Staphylococcal aureus. Toxin gene analysis subsequently confirmed the presence of the superantigen exotoxin, toxic shock syndrome toxin-1 (TSST-1).

In the intensive care unit, her management was complicated by an acute kidney injury requiring renal replacement therapy, a sepsis-associated coagulopathy, septic encephalopathy, transient cardiomyopathy, and thyrotoxicosis. Adult respiratory distress syndrome and a Pseudomonas aeruginosa pneumonia further complicated this patient's recovery. Following two failed extubation attempts and difficulty to wean from ventilatory support, a tracheostomy was sited. This patient was eventually decannulated and discharged to the paediatric ward following a 1-month critical care admission.

\section{Discussion}

Toxic shock syndrome (TSS) is an acute, multisystem, toxinmediated condition often preceded by a prodromal influenzalike illness, leading to rapid-onset shock, erythroderma, and accelerated multiorgan failure.

Staphylococcal TSS was first described among a cohort of young women inthe USA in the 1980s and was associated with the use of super-absorbent tampon material [1].

Bacterial toxins act as highly virulent superantigens that trigger massive immune cell activation and cytokine release 
resulting in distributive shock and multiorgan failure. In 95\% of menstrual cases of TSS, staphylococcal TSST-1 is the causative agent [2]. Host antibody deficiency is also recognised as an important factor in the development of fulminant TSS $[2,3]$.

Therapeutic strategies include early aggressive resuscitation, supportive management, and source control $[2,4,5]$. Surgical debridement may be necessary if tissue infection is established. Vaginal examination and foreign body removal should be considered in female patients. Antibiotic therapy should focus on reducing bacterial load and exotoxin production. Specific antimicrobial therapies such as clindamycin or linezolid (these neutralize TSST1 production) and intravenous immunoglobulin have been shown to improve survival in TSS and their early use is recommended $[4,5]$.

Despite changes in the design of female sanitary products and a consequent decline in the incidence of staphylococcal TSS, cases of menses-associated TSS still occur [2]. Emergency physicians should maintain a high index of suspicion in all women using catamenial products that present with these symptoms. Recurrent TSS has been reported and these women should be advised against future use of tampons.

\section{Conflict of Interests}

The authors declare that there is no conflict of interests regarding the publication of this paper.

\section{References}

[1] M. T. Osterholm, J. P. Davis, R. W. Gibson, J. C. Forfang, S. J. Stolz, and J. M. Vergeront, "Toxic shock syndrome: relation to catamenial products, personal health and hygiene, and sexual practices," Annals of Internal Medicine, vol. 96, no. 6, part 2, pp. 954-958, 1982.

[2] E. Lappin and A. J. Ferguson, "Gram-positive toxic shock syndromes," The Lancet Infectious Diseases, vol. 9, no. 5, pp. 281290, 2009.

[3] A. J. Brosnahan and P. M. Schlievert, "Gram-positive bacterial superantigen outside-in signaling causes toxic shock syndrome," The FEBS Journal, vol. 278, no. 23, pp. 4649-4667, 2011.

[4] M. Llewelyn and J. Cohen, "Superantigens: microbial agents that corrupt immunity," The Lancet Infectious Diseases, vol. 2, no. 3, pp. 156-162, 2002.

[5] T. Shalaby, S. Anandappa, N. J. Pocock, A. Keough, and A. Turner, "Lesson of the month 2: toxic shock syndrome," Clinical Medicine, vol. 14, no. 3, pp. 316-318, 2014. 


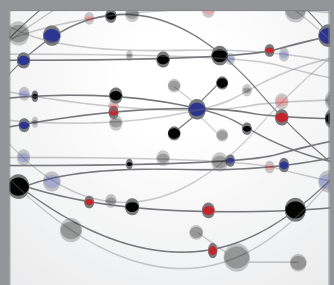

The Scientific World Journal
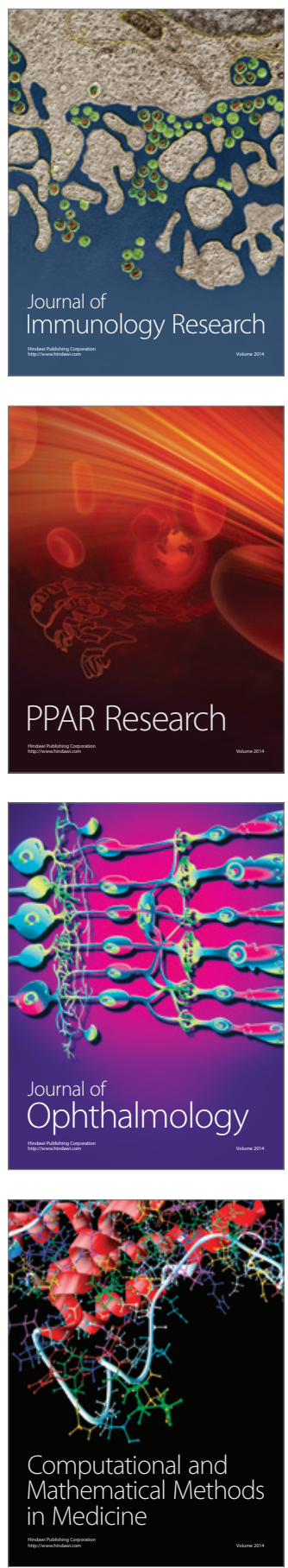

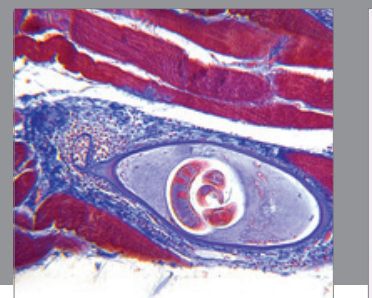

Gastroenterology

Research and Practice
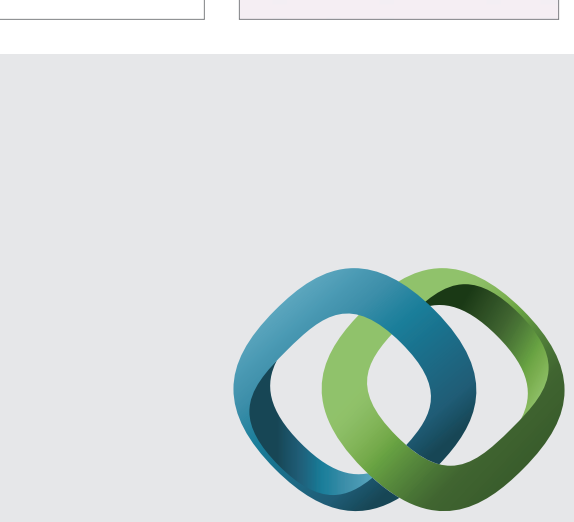

\section{Hindawi}

Submit your manuscripts at

http://www.hindawi.com
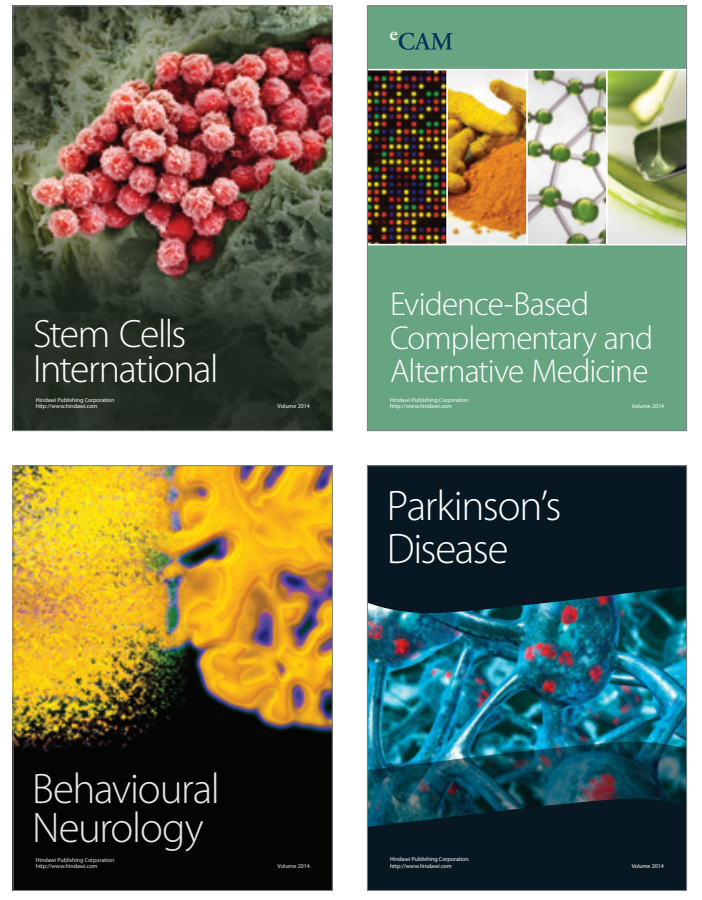
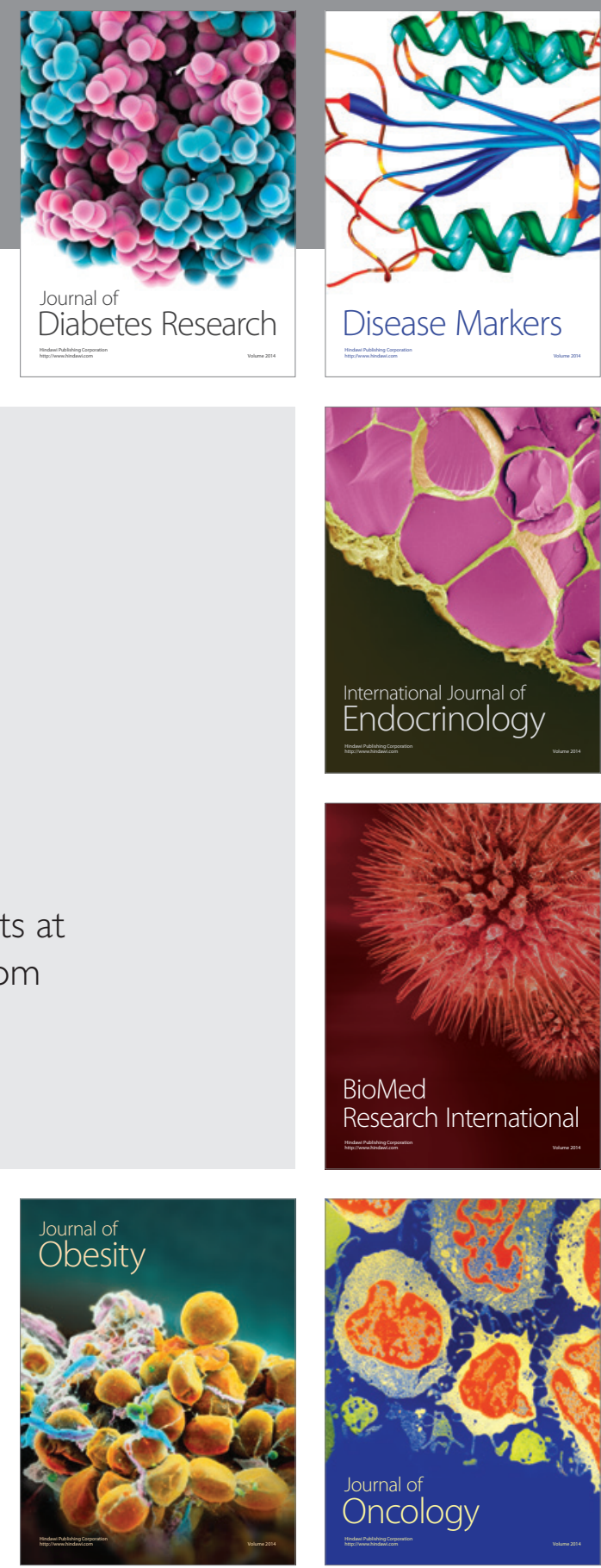

Disease Markers
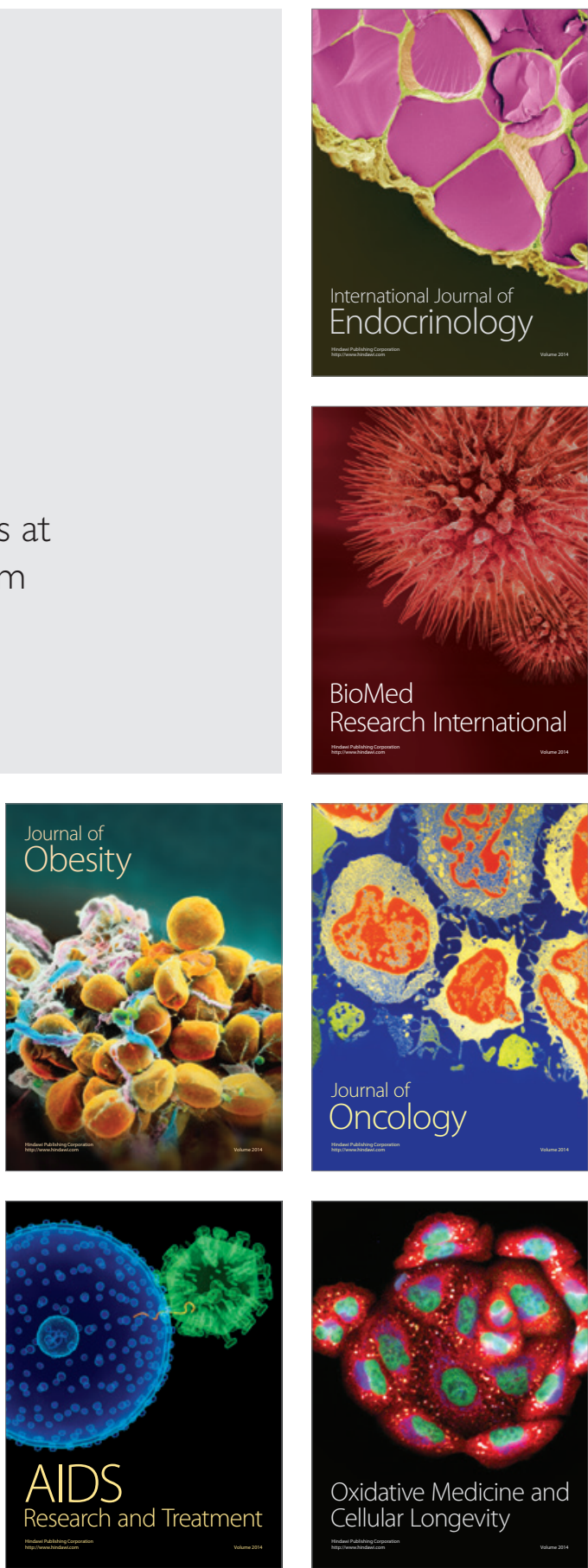